\title{
Short communication: Novel method to predict body weight of primiparous dairy cows throughout the lactation
}

\author{
M.-L. Vanrobays, ${ }^{* 1}$ J. Vandenplas, ${ }^{*} \dagger$ H. Hammami, ${ }^{*} \dagger$ E. Froidmont, $\ddagger$ and N. Gengler ${ }^{*}$ \\ ${ }^{*}$ Animal Science Unit, Gembloux Agro-Bio Tech, University of Liege, B-5030 Gembloux, Belgium \\ †National Fund for Scientific Research, B-1000 Brussels, Belgium \\ ¥Walloon Agricultural Research Centre, Production and Sectors Department, B-5030 Gembloux, Belgium
}

\section{ABSTRACT}

Body weight (BW) of dairy cows can be estimated using linear conformation traits (calculated BW; $\mathrm{CBW}$ ), which are generally recorded only once during a lactation. However, predicted BW (PBW) throughout the lactation would be useful, e.g., at milk-recording dates allowing feed-intake prediction for advisory purposes. Therefore, a 2-step approach was developed to obtain PBW for each milk-recording date. In the first step, a random-regression test-day model was used with CBW as observations to predict PBW. The second step consisted in changing means and (co)variances of prior distributions for the additive genetic random effects of the test-day model by using priors derived from results of the first step to predict again PBW. A total of 25,061 CBW from 24,919 primiparous Holstein cows were computed using equations from literature. Using CBW as observations, PBW was then predicted over the whole lactation for 232,436 dates corresponding to 207,375 milk-recording dates and 25,061 classification dates. Results showed that using both steps (the 2-step approach) provided more accurate predictions than using only the first step (the one-step approach). Based on the results of this preliminary study, BW of dairy cows could be predicted throughout the lactation using this procedure. These predictions could be useful in milk-recording systems to compute traits of interest (e.g., feed-intake prediction). The developed novel method is also flexible because actual direct measurements of BW can also be used together with CBW, the prediction model being able to accommodate different levels of accuracies of used BW phenotypes.

Key words: dairy cattle, body weight, feed intake, Bayesian prediction model

Received June 19, 2014.

Accepted September 22, 2014.

${ }^{1}$ Corresponding author: mlvanrobays@ulg.ac.be

\section{Short Communication}

Because milk-production costs are mainly influenced by feeding charges, interest is growing in improving feed efficiency of dairy cows. Dry matter intake appears to be an interesting trait for management purposes and could be included in breeding schemes (Pryce et al., 2014). However, direct DMI measurements are expensive and difficult. Several models were developed to estimate feed intake of dairy cows based on animal factors or diet characteristics (Huhtanen et al., 2011). Body weight of dairy cows influences their DMI through different ways. First, BW reflects the capacity of the digestive tract (Zom et al., 2012). Also, because of increased maintenance cost, heavier animals tend to eat more. For these reasons, BW is often used in predictive models of DMI. Hence, the NRC (2001) provided a model that estimates DMI only from variables related to the animal (i.e., fat- and protein-corrected milk yield, lactation stage, and BW). This model would be useful in milk-recording programs, but BW has to be routinely collected or, at least, reasonable estimates have to be available. However, in the Walloon Region of Belgium, as in many countries, BW is not routinely recorded on farms. Although it might be recorded in automatic milking systems, these data are not transferred to performance-recording databases. Nevertheless, it has been shown that BW can be estimated from linear conformation traits, hereafter called calculated BW (CBW; e.g., Koenen and Groen, 1998; Banos and Coffey, 2012; Haile-Mariam et al., 2014). Most of the equations developed to generate CBW take into account the lactation stage in addition to conformation traits. However, at least 3 issues exist related to CBW of classified cows: i) CBW are less precise than actual weightings of cows; ii) each CBW is associated with a classification date and therefore it is not directly available for the day when milk production is recorded; and iii) $\mathrm{BW}$ is highly variable inside a given lactation for a given cow, which has to be considered when estimating BW throughout the lactation. The first issue is difficult to address because modern production systems 
seldom measure or transfer animal weights, leading to a more widespread use of CBW (e.g., Haile-Mariam et al., 2014). The last 2 issues are currently overlooked, although they are extremely important for the practical use of BW, e.g., in computing DMI for every date of milk recording (test date). Therefore, because CBW is generally not related to a test date, the objective of this study was to develop a novel method to predict BW (PBW) throughout lactation of cows using initial CBW records based on conformation traits.

Linear conformation data (i.e., angularity, chest width, stature, body depth, and BCS) of cows were collected at the same day by the Walloon Breeding Association (Ciney, Belgium). A total of 25,061 linear conformation records from 24,919 first-lactation Holstein cows belonging to 622 herds in the Walloon Region of Belgium were available. Very few animals were classified more than once during their first lactation. Test-date records of studied cows provided by the Walloon Breeding Association from milk recording were then merged with the conformation-traits data set to identify dates when milk recording occurred. The final data set included DIM, birth date, calving date, and test or classification date, corresponding to the dates for which PBW had to be estimated. This data set was organized to estimate from 25,061 CBW a total of 232,436 PBW at 207,375 test dates and 25,061 classification dates. Pedigree data for these cows were extracted from the database used for the official Walloon genetic evaluation. The pedigree file contained 124,863 animals. Two existing equations developed by Laloux (2008), and currently used by the Walloon Breeding Association, were applied on linear conformation data and age of dairy cows to estimate CBW of cows at their classification date. The coefficient of determination $\left(\mathrm{R}^{2}\right)$ of the first equation, which was based on age, angularity, chest width, stature, body depth, and BCS, was 0.86 . This equation was applied to cows at DIM $\leq 130 \mathrm{~d}$. The second equation, applied to cows at DIM $>130$ d, was based on age, angularity, stature, body depth, and BCS and had a $\mathrm{R}^{2}$ of 0.73 (Laloux, 2008). These 2 different lactation periods will be called hereafter early (EL) and mid-late (ML) lactation periods. Because developing improved CBW equations was not the objective of this study, precise $R^{2}$ of the equations were not revalidated. For this reason, an approximate average $R^{2}$ of 0.80 was used in this initial study, even if the presented method permitted a different weight for each CBW record.

To predict PBW of cows across DIM using empirical Bayes predictions, the following weighted univariate random-regression test-day model was developed based on preliminary studies (results not shown):

$$
\begin{aligned}
\mathbf{y}=\mathbf{X b} & +\mathbf{d}_{\mathrm{l}} \alpha_{\mathrm{l}}+\mathbf{d}_{\mathrm{q}} \alpha_{\mathrm{q}}+\mathbf{Z}_{\mathrm{el}} \mathbf{h}_{\mathrm{el}}+\mathbf{Z}_{\mathrm{ml}} \mathbf{h}_{\mathrm{ml}} \\
& +\mathbf{Z}_{\mathrm{el}} \mathbf{a}_{\mathrm{el}}+\mathbf{Z}_{\mathrm{ml}} \mathbf{a}_{\mathrm{ml}}+\mathbf{e},
\end{aligned}
$$

where $\mathbf{y}$ was the vector of observations (i.e., CBW); $\mathbf{b}$ was the vector of fixed effects including year of milkrecording date or classification date, season of milkrecording date or classification date (4 seasons defined as winter for December, January, and February; spring for March, April, and May; summer for June, July, and August; and autumn for September, October, and November), classes of gestation stage (4 classes including nongestating cows, early-gestating cows, late-gestating cows, and no information about gestation status of cows), and age at calving $\times$ lactation stage $(6$ classes of age at calving defined as lower than 25 mo, between 25 and 27 mo, between 28 and 30 mo, between 31 and 33 mo, between 34 and $36 \mathrm{mo}$, and higher than 36 mo and 3 classes of 122 DIM); $\mathbf{d}_{1}$ and $\mathbf{d}_{\mathrm{q}}$ were linear and quadratic regression variables expressed as linearized evolutions of average smoothed weight across DIM; and $\alpha_{1}$ and $\alpha_{\mathrm{q}}$ were associated fixed regression coefficients. The model contained 2 correlated random-regression herd effects $\left(\mathbf{h}_{\mathrm{el}}\right.$ and $\left.\mathbf{h}_{\mathrm{ml}}\right)$ and 2 random-regression animal genetic effects $\left(\mathbf{a}_{\mathrm{el}}\right.$ and $\left.\mathbf{a}_{\mathrm{ml}}\right)$, for EL and ML lactation periods. Finally, e was the vector of residuals, and $\mathbf{X}, \mathbf{Z}_{\mathrm{el}}$, and $\mathbf{Z}_{\mathrm{ml}}$ were incidence matrices assigning observations to fixed and random effects. Model [1] was equivalent to a bi-period (EL vs. ML lactation) testday model sharing fixed effects.

Because preliminary studies showed heterogeneity of residual variances (data not shown) reflecting also different $R^{2}$ of equations from Laloux (2008), observations were weighted with their respective residual variances according to the fact that they were obtained in EL or ML lactation periods. It was assumed that $\mathbf{h}_{\mathrm{el}}$ and $\mathbf{h}_{\mathrm{ml}}$ followed a multivariate normal (MVN) distribution, $\operatorname{MVN}\left(\left[\begin{array}{l}\mathbf{0} \\ \mathbf{0}\end{array}\right], \mathbf{I} \otimes \mathbf{H}_{0}\right)$, where $\mathbf{I}$ was an identity matrix and $\mathbf{H}_{0}$ was a (co)variance matrix among EL and ML lactation periods. It was also assumed that $\mathbf{a}_{\mathrm{el}}$ and $\mathbf{a}_{\mathrm{ml}}$ followed a MVN distribution, MVN $\left(\left[\begin{array}{l}\mathbf{0} \\ \mathbf{0}\end{array}\right], \mathbf{A} \otimes \mathbf{G}_{0}\right)$, where $\mathbf{G}_{0}$ was the (co)variance matrix among EL and ML lactation periods and $\mathbf{A}$ was the numerator relationships matrix.

Following the model [1] and the previous assumptions, variance components were estimated using EMREML implemented in the REMLF90 software (Misztal, 2012). Estimated relative herd variances were 0.26 $\mathrm{kg}^{2}$ for EL and ML lactation periods, and correlation across herd effects was 0.88. Estimated heritabilities for 
CBW were 0.14 in EL and ML lactation periods. A very high genetic correlation $(>0.99)$ was estimated between CBW in EL and ML lactation periods. This value can be explained by the fact that sires with heavier daughters in EL lactation are also siring heavier daughters in ML lactation.

First, a one-step approach was developed to predict BW (i.e., PBW1; Figure 1) based on the model [1] with the assumption that the prior distribution for the random effects $\mathbf{a}=\left[\begin{array}{l}\mathbf{a}_{\mathrm{el}} \\ \mathbf{a}_{\mathrm{ml}}\end{array}\right]$ followed a MVN distribution, $\mathbf{a}$ $\sim \operatorname{MVN}(\mathbf{0}, \mathbf{G})$, where $\mathbf{G}=\mathbf{A} \otimes \mathbf{G}_{0}$. Therefore, the PBW1 value obtained with the one-step procedure for a cow at a given date was equal to the sum of estimates for fixed effects and predictions for random effects obtained with the model [1] for that given date. Second, an innovative 2-step approach was developed to obtain PBW using a second step (i.e., PBW2; Figure 1) beyond the solutions provided by model [1]. The first step of the 2-step approach was equal to the one-step procedure. For the second step, solutions for a and e obtained from this first step are used to alter means and (co)variances of the prior distributions of the additive genetic random effects (Figure 1). Therefore, estimates of BW for specific test dates (i.e., PBW2) were obtained using the model [1] with prior distributions for random effects a as $\mathbf{a} \sim \operatorname{MVN}\left(\boldsymbol{\mu}, \mathbf{G}^{*}\right)$. Bayesian prediction theory as outlined by Henderson (1984) and used by others authors (e.g., Schaeffer and Jamrozik, 1996) was adapted following Vandenplas and Gengler (2012). For each ith level of a having an observation (i.e., CBW), the respective element for the vector $\boldsymbol{\mu}, \boldsymbol{\mu}_{i}$, was equal to the sum of $\hat{\mathbf{a}}_{i}$ and $\hat{\mathbf{e}}_{i}$ computed during the first step. If more than one CBW was available per cow and period, averaged solutions were used. Record equivalents (i.e., effective number of records representing accuracies of equations from Laloux, 2008) associated to $\boldsymbol{\mu}$ were assumed to be equal to $24 x$, where $x$ was the number of CBW records equivalent per cow and period during the first lactation. This approximate number was computed to reflect an assumed $\mathrm{R}^{2}$ of 0.80 associated to $\mathrm{CBW}$ using the following formula:

$$
f=\frac{\lambda \mathrm{R}^{2}}{1-\mathrm{R}^{2}}
$$

where $f$ was the assumed number of theoretical records and $\lambda$ was set to 6 just as the assumed variance ratio between the animal effect and the other effects given the heritabilities (0.14 for CBW in EL and ML lactation periods). The developed approach was equivalent to pushing virtually heritabilities to a higher level, in this study in line with average $\mathrm{R}^{2}$ of equations from

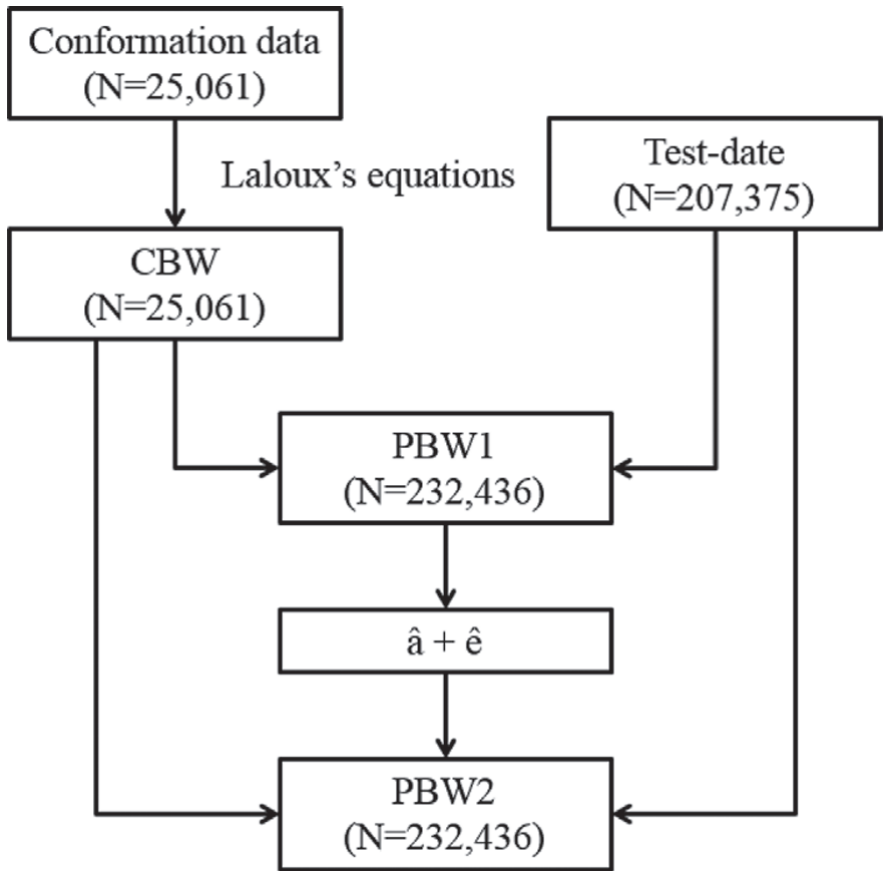

Figure 1. Flowchart summarizing the 2-step approach: (i) BW of dairy cows were calculated from 25,061 conformation data (CBW) with equations from Laloux (2008); (ii) 207,375 milk-recording data were available in first lactation for cows with conformation data; (iii) BW of dairy cows were predicted using the first-step approach (PBW1) for classification and milk-recording dates: PBW1 were predicted with a random regression test-day model with CBW as observations; (iv) BW of dairy cows were predicted again with the second-step approach (PBW2), which consisted of changing means and (co)variances of prior distributions for additive genetic random effects using priors developed from results provided by the first step $(\hat{\mathbf{a}}+\hat{\mathbf{e}})$, â and $\hat{\mathrm{e}}$ being the additive genetic and residual effects, respectively.

Laloux (2008; i.e., 0.80). By back solving in [2] for $f=$ 1 , a $\lambda$ ratio of 0.25 appears, which corresponds to a virtual heritability of 0.80 . The matrix $\mathbf{G}^{*}$ was computed as detailed by Vandenplas and Gengler (2012) for the first version of Bayesian evaluation. Solving of (modified-) mixed-model equations was done using sparse inversion as implemented in the software BLUPF90 (Misztal, 2012) adapted through modifications outlined by Vandenplas and Gengler (2012).

The root mean square difference (RMSD), the mean absolute difference (MAD), and the square of correlation coefficient $\left(\mathbf{R}_{c}^{2}\right)$ were used to compare CBW and PBW1 or PBW2 of cows from the one-step and the 2-step approaches, respectively. The RMSD and MAD were computed as follows (Willmott and Matsuura, 2005):

$$
\begin{aligned}
\text { RMSD } & =\sqrt{\frac{\sum_{i=1}^{n}\left|\varepsilon_{i}\right|^{2}}{n},} \\
\mathrm{MAD} & =\frac{\sum_{i=1}^{n}\left|\varepsilon_{i}\right|}{n},
\end{aligned}
$$




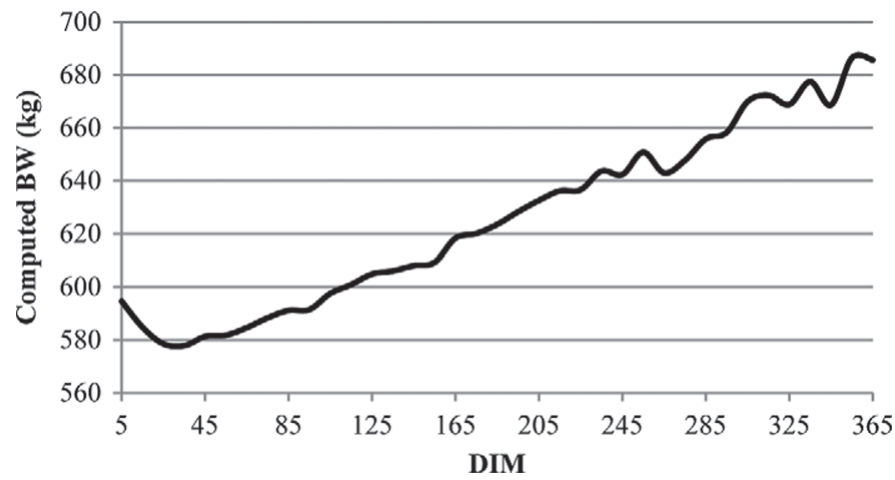

Figure 2. Averaged computed BW of dairy cows in first lactation across DIM estimated from equations based on conformation traits.

where $n$ was the number of CBW records and $\varepsilon_{i}$ was the difference between CBW and PBW1 or PBW2 for the ith observation.

To have additional information allowing comparisons between the fit of PBW1 and PBW2 and actual BW measurements not used in the prediction equation development, a small data set of 36 completely independent actual weightings from cows known in the system was obtained from the Walloon Agricultural Research Centre (Gembloux, Belgium) dairy farm. The $\mathrm{R}_{c}^{2}$ between actual BW and PBW1 and PBW2 estimated at the same dates for these cows were computed.

Figure 2 shows average daily $\mathrm{CBW}$ of dairy cows throughout DIM estimated using the 2 equations developed by Laloux (2008). These CBW were in the same range as actual BW measurements used by Laloux (2008) and followed the expected trend (decrease in early lactation and increase after; e.g., Coffey et al., 2003). The general trends of estimated average daily PBW1 (results not shown) and PBW2 (Figure 3) of dairy cows across DIM were similar to those observed for average daily CBW (Figure 2). The addition of a second step to the procedure was associated with a smaller RMSD and MAD and a higher $\mathrm{R}_{c}^{2}$ between CBW and PBW2 (Table 1). This is a desired feature, because BW curves represented by PBW throughout the lactation should not deviate from CBW. Figure 4 illustrates that the prediction of $\mathrm{BW}$ for a cow with 2 observed CBW was better using the 2-step approach (PBW2) than using only the one-step approach (PBW1). As shown in this figure, with the one-step approach, PBW1 was regressed toward expected mean BW [i.e., the expectation $\mathrm{E}\left(\mathbf{X b}+\mathbf{d}_{1} \alpha_{1}+\mathbf{d}_{\mathrm{q}} \alpha_{\mathrm{q}}\right)$ ] for a known CBW, leading to suboptimal PBW1 estimates because they deviate from observed CBW. By adding the second step, i.e., by altering the means and (co) variances of prior distributions for a, deviation of predicted PBW2 from observed CBW is strongly reduced.

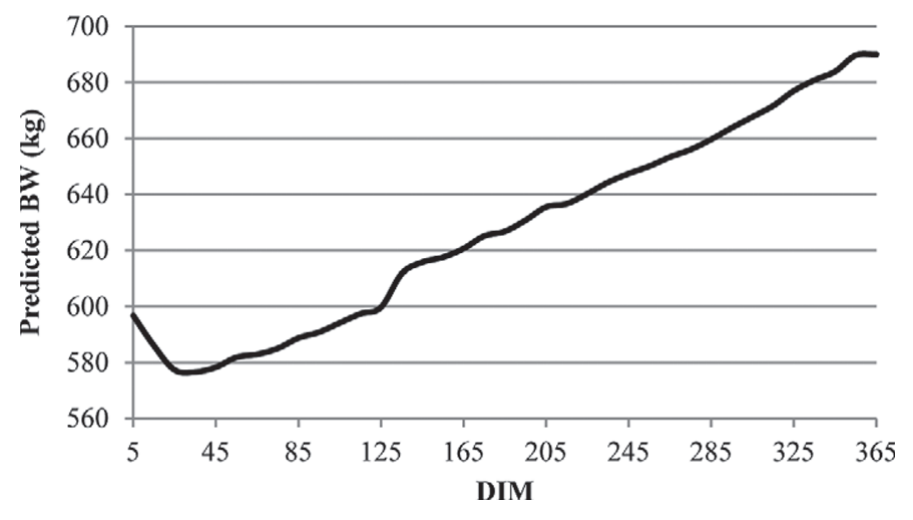

Figure 3. Predicted average BW of dairy cows in first lactation across DIM obtained through the second step of the prediction procedure.

When using the one-step approach, higher average RMSD per class of 10 DIM were found for ML lactation period [corresponding to the second equation of Laloux (2008); mean of RMSD $=41.27 \mathrm{~kg}$ ] than for EL lactation period [related to the first equation of Laloux (2008); mean of RMSD $=30.70 \mathrm{~kg}$. This difference could be due to lower accuracy of the ML-lactationperiod equation compared with the EL-lactation-period equation ( 0.73 vs. 0.86 , respectively). In the opposite, average RMSD per class of 10 DIM from the 2-step approach were similar between EL and ML lactation periods. Therefore, by adding a second step, a reduction of the heterogeneity of residual variance seems to be achieved.

The first results obtained with this novel approach were validated with actual independent BW measurements. An initial comparison showed that the $\mathrm{R}_{c}^{2}$ between actual BW measurements and PBW2 of cows was higher in comparison to the $\mathrm{R}_{c}^{2}$ between actual BW measurements and PBW1 (0.897 vs. 0.575, respectively). Therefore, adding the second step predicted more accurately the actually measured BW than using the first step only.

This study showed that BW throughout lactation of dairy cows could be predicted based on CBW from linear conformation traits. The 2-step approach provided better estimates (PBW2) than using only a regular

Table 1. Root mean square difference (RMSD), mean absolute difference (MAD), and square of correlation coefficient $\left(\mathrm{R}^{2}\right)$ between 25,061 observed BW of dairy cows in first lactation calculated from equations based on conformation traits and corresponding BW predicted with the 1-step and the 2-step approaches

\begin{tabular}{lccc}
\hline Approach & RMSD $(\mathrm{kg})$ & $\mathrm{MAD}(\mathrm{kg})$ & $\mathrm{R}_{c}^{2}$ \\
\hline 1-Step & 35.90 & 27.98 & 0.916 \\
2-Step & 3.51 & 1.94 & 0.999 \\
\hline
\end{tabular}


$\triangle \mathrm{CBW}-\mathrm{PBW} 1 \times \mathrm{PBW} 2$

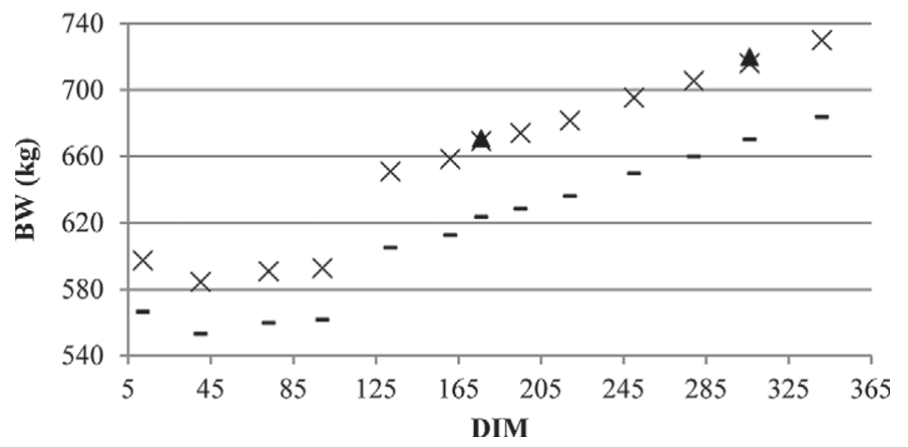

Figure 4. Daily BW for a given cow estimated from equations based on conformation traits (CBW) and from the prediction procedure (PBW) across DIM using the first-step (PBW1) and the secondstep (PBW2) approaches of the prediction procedure.

mixed model (here called the one-step approach). By adding a second step, PBW (called PBW2) were better predicted than PBW1 because PBW2 fitted better to known CBW. Modifications in the second step of the 2-step approach consisted of changing the means and (co)variances of the prior distributions of the additive genetic random effects when doing the empirical Bayesian prediction. Therefore, the 2-step approach was found to be an appropriate tool to generate PBW to predict traits based on BW such as daily DMI of dairy cows within regular milk-recording schemes. This would also allow the inclusion of traits derived from BW in appropriate breeding schemes. Obviously, PBW are also dependent on the quality of CBW used as input. Therefore, further research is required to improve and validate the equations used to derive CBW from conformation traits. However, the presented procedure is also extremely flexible because actual weightings (e.g., BW generated through automatic milking systems) could be used together with CBW, each piece of information being associated with a different level of accuracy.

In most countries, only first-lactation animals are classified. However, at least in the Walloon Region of Belgium, classification might be extended to laterlactation animals when these data are used for mating purposes. The extension of the method to later lactations using CBW computed for multiparous cows will be straightforward using adapted multilactation models. This would also allow predicting BW and therefore expected DMI at a larger scale. Consequently, the present research could also be complementary to research efforts on energy efficiency by linking expected (residual) feed intake to methane emissions. This is of great interest considering that those emissions can be predicted from milk composition (Dehareng et al.,
2012) and they are, therefore, available together with expected DMI at milk-recording dates.

\section{ACKNOWLEDGMENTS}

Financial support was provided by the Ministry of Agriculture of Walloon Region of Belgium (Service Public de Wallonie, Direction générale opérationnelle "Agriculture, Ressources naturelles et Environnement" - DGARNE) through research projects D31-1248 and D31-1304. Jérémie Vandenplas, as a research fellow, Hedi Hammami, as a postdoctoral researcher, and Nicolas Gengler, as a former senior research associate, acknowledge the support of the National Fund for Scientific Research (Brussels, Belgium) for these positions. The authors thank the Walloon Breeding Association (Ciney, Belgium) for providing access to milk-recording data. The authors are grateful to the Consortium des Équipements de Calcul Intensif (CÉCI), funded by the National Fund for Scientific Research (Brussels, Belgium) under Grant No. 2.5020.11, for the use of their supercomputers. Catherine Bastin (Gembloux AgroBio Tech, University of Liege, Gembloux, Belgium) is acknowledged for manuscript review.

\section{REFERENCES}

Banos, G., and M. P. Coffey. 2012. Technical note: Prediction of liveweight from linear conformation traits in dairy cattle. J. Dairy Sci. 95:2170-2175. http://dx.doi.org/10.3168/jds.2011-4838.

Coffey, M. P., G. Simm, W. G. Hill, and S. Brotherstone. 2003. Genetic evaluations of dairy bulls for daughter energy balance profiles using linear type scores and body condition score analyzed using random regression. J. Dairy Sci. 86:2205-2212. http://dx.doi. org/10.3168/jds.S0022-0302(03)73810-7.

Dehareng, F., C. Delfosse, E. Froidmont, H. Soyeurt, C. Martin, N. Gengler, A. Vanlierde, and P. Dardenne. 2012. Potential use of milk mid-infrared spectra to predict individual methane emission of dairy cows. Animal 6:1694-1701. http://dx.doi.org/10.1017/ S1751731112000456.

Haile-Mariam, M., O. Gonzalez-Recio, and J. E. Pryce. 2014. Prediction of liveweight of cows from type traits and its relationship with production and fitness traits. J. Dairy Sci. 97:3173-3189. http:// dx.doi.org/10.3168/jds.2013-7516.

Henderson, C. R. 1984. Applications of Linear Models in Animal Breeding. 2nd ed. Univ. Guelph, Guelph, ON, Canada.

Huhtanen, P., M. Rinne, P. Mäntysaari, and J. Nousiainen. 2011. Integration of the effects of animal and dietary factors on total dry matter intake of dairy cows fed silage-based diets. Animal 5:691702. http://dx.doi.org/10.1017/S1751731110002363.

Koenen, E. P. C., and A. F. Groen. 1998. Genetic evaluation of body weight of lactating Holstein heifers using body measurements and conformation traits. J. Dairy Sci. 81:1709-1713. http://dx.doi. org/10.3168/jds.S0022-0302(98)75738-8.

Laloux, L. 2008. Elaboration de formules de prédiction du poids vif des vaches en lactation à partir des cotes de classifications linéaires et du BCS. AWE Internal Report, Ciney, Belgium.

Misztal, I. 2012. BLUPF90 Family of Programs. Accessed Dec. 2012. http://nce.ads.uga.edu/wiki/doku.php/.

NRC. 2001. Nutrient Requirements of Dairy Cattle. Natl. Acad. Press, Washington, DC. 
Pryce, J. E., W. J. Wales, Y. de Haas, R. F. Veerkamp, and B. J. Hayes. 2014. Genomic selection for feed efficiency in dairy cattle. Animal 8:1-10. http://dx.doi.org/10.1017/S1751731113001687.

Schaeffer, L. R., and J. Jamrozik. 1996. Multiple-trait prediction of lactation yields for dairy cows. J. Dairy Sci. 79:2044-2055. http://dx.doi.org/10.3168/jds.S0022-0302(96)76578-5.

Vandenplas, J., and N. Gengler. 2012. Comparison and improvements of different Bayesian procedures to integrate external information into genetic evaluations. J. Dairy Sci. 95:1513-1526. http:// dx.doi.org/10.3168/jds.2011-4322.
Willmott, C. J., and K. Matsuura. 2005. Advantages of the mean absolute error (MAE) over the root mean square error (RMSE) in assessing average model performance. Clim. Res. 30:79-82.

Zom, R. L. G., G. André, and A. M. van Vuuren. 2012. Development of a model for the prediction of feed intake by dairy cows 2 . Evaluation of prediction accuracy. Livest. Sci. 143:58-69. http:// dx.doi.org/10.1016/j.livsci.2011.08.013. 